CLINICAL STUDY

\title{
Repeated colonoscopic screening of patients with acromegaly: 15-year experience identifies those at risk of new colonic neoplasia and allows for effective screening guidelines
}

\author{
D Dworakowska ${ }^{1,2}$, M Gueorguiev ${ }^{1}$, P Kelly ${ }^{1}$, J P Monson ${ }^{1}$, G M Besser ${ }^{1}$, S L Chew ${ }^{1}$, S A Akker ${ }^{3}$, W M Drake ${ }^{3}$, \\ $\mathrm{P}^{\mathrm{D}}$ Fairclough ${ }^{4}$, A B Grossman ${ }^{1}$ and P J Jenkins ${ }^{1}$ \\ ${ }^{1}$ Department of Endocrinology, Barts and The London School of Medicine, 68 Harley Street, London EC1A 7BE, UK, ${ }^{2}$ Department of Endocrinology and \\ Internal Medicine, Medical University of Gdańsk, 7 Dẹbinki Str. 80-210 Gdańsk, Poland and Departments of ${ }^{3}$ Endocrinology and ${ }^{4}$ Gastroenterology, Barts \\ and The London NHS Trust, London EC1A 7BE, UK \\ (Correspondence should be addressed to P J Jenkins; Email: p.j.jenkins@qmul.ac.uk)
}

\begin{abstract}
Objective: It is suggested that patients with acromegaly have an increased risk of colorectal cancer and pre-malignant adenomatous polyps. However, the optimum frequency with which colonoscopic screening should be offered remains unclear.

Design: To determine the optimum frequency for repeated colonoscopic surveillance of acromegalic patients.

Methods: We retrospectively reviewed the case records of all patients with acromegaly seen in our centre since 1992: 254 patients had at least one surveillance colonoscopy, 156 patients had a second surveillance colonoscopy, 60 patients had a third surveillance colonoscopy and 15 patients had a fourth surveillance colonoscopy.

Results: The presence of hyperplastic or adenomatous polyps was assessed in all patients, while one cancer was detected at the second surveillance. At the third surveillance, mean ( \pm s.D.) serum IGF1 levels $(\mathrm{ng} / \mathrm{ml})$ in patients with hyperplastic polyps were significantly higher than those with normal colons $(P<0.05)$. The presence of an adenoma rather than a normal colon at the first colonoscopy was associated with a significantly increased risk of adenoma at the second (odds ratio (OR) 4.4, 95\% confidence interval (CI) 1.9-10.4) and at the third (OR 8.8, 95\% CI 2.9-26.5) screens. Conversely, a normal colon at the first surveillance gave a high chance of normal findings at the second (78\%) or third surveillance (78\%), and a normal colon at the second colonoscopy was associated with normality at the third colonoscopy $(81 \%)$.

Conclusions: Repeated colonoscopic screening of patients with acromegaly demonstrated a high prevalence of new adenomatous and hyperplastic colonic polyps, dependent on both the occurrence of previous polyps and elevated IGF1 levels.
\end{abstract}

European Journal of Endocrinology 163 21-28

\section{Introduction}

Acromegaly is associated with increased morbidity and mortality. Several previous studies have suggested that these patients are also at an increased risk of neoplasia, especially colorectal cancer and pre-malignant adenomatous polyps, although the degree of risk remains under debate (1-12). In our original series, we observed $5 \%$ to have a carcinoma and $25 \%$ to have one or more adenomas (11). Similar findings have been reported by other groups (12). In the non-acromegalic population, the vast majority of colorectal cancers derive from adenomatous polyps through the progressive accumulation of mutations in oncogenes and tumour suppressor genes, a process that takes $\sim 10-20$ years $(13,14)$. More recently, hyperplastic polyps, which were previously considered to have no malignant potential, have also been shown to either undergo malignant transformation or be associated with an increased risk of future neoplasia $(15,16)$. Taken together, this implies that with adequate surveillance colon cancer may, at least in part, be a preventable disease, since several studies have demonstrated that the colonoscopic screening and removal of colonic polyps reduce the incidence of colorectal cancer (17). Many endocrinologists and gastroenterologists therefore recommend this procedure to patients with acromegaly, a view endorsed by a recent consensus document (18). However, the frequency with which colonoscopic screening should be offered remains unclear. We have previously suggested 3-5 yearly intervals, starting over the age of 40 years, based on serum insulin-like growth factor 1 (IGF1) 
levels and the presence of previous neoplasia (19). However, the length of follow-up of these patients was relatively short. As we now have a much longer duration of experience of our colonoscopic screening programme, the aims of the current study were i) to review the optimum frequency for repeated colonoscopic surveillance of acromegalic patients, ii) to determine the influence of serum IGF1 levels and iii) to establish the role of previous neoplasia on the development of new neoplasia.

\section{Patients and methods}

\section{Patients}

Since 1992, 254 patients (mean age 56.6 years) at our centre have undergone at least one surveillance colonoscopy; 156 patients (mean age 61.8 years) have undergone a second colonoscopy at a mean interval of 4.4 years (range $0.3-10.8$ years); 60 patients (mean age 65.3 years) have undergone a third study at a mean interval after the second colonoscopy of 4.0 years (range 0.4-7.5 years), while 15 patients have undergone a fourth surveillance at a mean interval of 3.3 years after the third surveillance. Patient details and endocrine status are given in Table 1. All patients were offered surveillance according to our previous recommendations based on the presence of colonic neoplasia and serum IGF1 levels, i.e. patients with elevated IGF1 levels or who had an adenoma detected were offered repeat colonoscopy after 3 years, while patients with a normal colon or hyperplastic polyp, and serum IGF1 levels within the normal range, were offered repeat colonoscopy after 5 years.

Table 1 Demographics of patients undergoing repeated colonoscopic screening.

\begin{tabular}{|c|c|c|c|c|}
\hline & \multicolumn{4}{|c|}{ Colonoscopic screen } \\
\hline & First & Second & Third & Fourth \\
\hline No. of patients & 254 & 156 & 60 & 15 \\
\hline $\begin{array}{l}\text { Mean age } \\
\quad(\text { years (S.D.)) }\end{array}$ & $56.6(11)$ & $61.9(10)$ & $65.3(10)$ & $71.2(9)$ \\
\hline $\begin{array}{l}\text { Mean interval } \\
\text { between } \\
\text { colonoscopies } \\
\text { (years (s.D.)) }\end{array}$ & - & $4.4(1.9)$ & $4.0(1.1)$ & $3.3(1.5)$ \\
\hline $\begin{array}{l}\text { Mean cumulative } \\
\text { interval (years) }\end{array}$ & - & 4.4 & 8.4 & 11.7 \\
\hline $\begin{array}{l}\text { Mean GH } \\
\quad(\mathrm{ng} / \mathrm{ml} \text { (s.D.)) }\end{array}$ & $5.5(13.2)$ & $2.2(2.1)$ & $2.0(2.3)$ & $1.9(1.2)$ \\
\hline $\begin{array}{l}\text { Mean IGF1 } \\
\quad(\text { ng/ml (s.D.)) }\end{array}$ & $328(232)$ & $248(141)$ & 242 (123) & $229(68)$ \\
\hline $\begin{array}{l}\text { Mean IGF1 } \\
\quad(\% \text { of ULN (s.D.)) }\end{array}$ & $127(80)$ & $99(50)$ & $101(50)$ & $101(30)$ \\
\hline $\begin{array}{l}\text { No. of subjects (\%) } \\
\text { with elevated } \\
\text { serum IGF1 } \\
(>\text { ULN) }\end{array}$ & $111(43)$ & $60(38)$ & $27(45)$ & $6(40)$ \\
\hline
\end{tabular}

ULN, upper limit of age-corrected normal range.

\section{Bowel preparation}

All patients received $2 \mathrm{l}$ of the osmotic purgative 'KleanPrep' (Norgine Ltd, Harefield, UK) at 6, 4 and $2 \mathrm{~h}$ (total $6 \mathrm{l}$ or more) prior to the procedure, with a liquid-only diet for $24 \mathrm{~h}$ beforehand. Oral iron was stopped at least 1 week before the start of the preparation. Except for two examinations performed elsewhere, all colonoscopic examinations were performed using an Olympus (Southend-on-Sea, UK) long colonoscope (CF IOTL or CF 230L) by the same operator (P D F). The ileo-caecal valve was visualised in $99 \%$ of procedures. Any lesion visualised was recorded and removed by snare diathermy or hot biopsy, and placed in formalin for subsequent histological assessment.

\section{GH and IGF1 measurements}

Serum IGF1 was assayed using an in-house RIA after formic acid-acetone extraction, as previously described (20). Age-related reference ranges were established in the same laboratory using serum derived from 150 healthy blood donors. The inter- and intra-assay coefficients of variation (CV) were $<10 \%$. Serum GH was measured using a two-site chemiluminescent enzyme immunometric assay on the Immulite 2000 auto-analyser (Euro/DPC Ltd, Gwynedd, UK). This uses the World Health Organization First International Reference Preparation 80/505 with a conversion factor of 2.6 for $\mathrm{ng} / \mathrm{ml}$ to $1 \mathrm{mIU} / \mathrm{l}$. The inter- and intra-assay $\mathrm{CV}$ were $<4$ and $6 \%$ respectively. GH values were taken as the mean of five measurements taken over a 12-h period. GH levels were not measured in patients being treated with pegvisomant, and these were discounted from analysis of GH effects.

\section{Statistical analysis}

Normality of data was assessed by the KolmogorovSmirnov test using the SPSS 8.0 (Chicago, IL, USA) software package. The Student's t-test was used for between-group comparison of normally distributed data, while analysis of non-parametric data was performed using the Mann-Whitney $U$ test and Fisher's exact test. Significance was taken as $P<0.05$. Odds ratios (ORs) were calculated using the SPSS 8.0 and Statistica 8.0 software based on logistic regression model.

\section{Results}

At the first colonoscopy, 10 patients were found to have a cancer, and an additional $89(35 \%)$ patients were found to have a polyp - 39 patients $(15 \%)$ with a hyperplastic and 50 patients $(20 \%)$ with an adenoma. At the second, third and fourth colonoscopies, the number (\%) of patients with hyperplastic or adenomatous polyps respectively was as follows: second colonoscopy $-31(20 \%)$ and $24(15 \%)$ of patients 
Table 2 Histological findings at sequential colonoscopic screenings: number of patients (\%).

\begin{tabular}{lcccc}
\hline & \multicolumn{4}{c}{ Colonoscopic screen } \\
\cline { 2 - 5 } Histology & First & Second & Third & Fourth \\
\hline Normal & $157(62)$ & $100(64)$ & $38(63)$ & $8(53)$ \\
Hyperplastic polyp & $39(15)$ & $31(20)$ & $14(23)$ & $3(20)$ \\
Adenomatous polyp & $50(20)$ & $24(15)$ & $8(14)$ & $4(27)$ \\
Cancers & $10(3)$ & $1(1)$ & 0 & 0 \\
\hline
\end{tabular}

respectively; third colonoscopy - $14(23 \%)$ and $8(14 \%)$ patients; fourth colonoscopy - $3(20 \%)$ and $4(27 \%)$ patients (Table 2). One cancer was detected at the second surveillance, but no other cancers were found. There was no association between colonoscopic findings and patient age or gender at any of the screening procedures.

\section{Location of polyps, size and dysplasia}

Of the adenomas at the first colonoscopy, $18 \%$ were situated in the caecum or ascending colon, compared with $33 \%$ at the second colonoscopy and $25 \%$ at the third colonoscopy. Histology revealed that the proportion of adenomas with moderate or severe cellular dysplasia at the first, second and third screenings was 36,22 and $25 \%$ respectively. The mean (range) size of the adenomas at the second and third colonoscopies was $4.4(2-8) \mathrm{mm}$ and $5(2-10) \mathrm{mm}$ respectively.

\section{Association with GH and IGF1 levels}

Table 3 shows the mean serum GH levels and proportion of patients with elevated (mean value $>2.5 \mathrm{ng} / \mathrm{ml}$ )

Table 3 Mean (s.D.) serum GH levels ( $\mathrm{ng} / \mathrm{ml}$ ) and number (\%) of patients with elevated GH levels $(>2.5 \mathrm{ng} / \mathrm{ml}$ ) in those with normal colons, hyperplastic polyps and adenomas at sequential colonoscopic screenings.

\begin{tabular}{|c|c|c|c|}
\hline & Normal & $\begin{array}{l}\text { Hyperplastic } \\
\text { polyps }\end{array}$ & $\begin{array}{l}\text { Tubular } \\
\text { adenomas }\end{array}$ \\
\hline \multicolumn{4}{|l|}{ First colonoscopy } \\
\hline Mean (S.D.) GH & $4.0(7.3)$ & $13.9(27.3)^{\star}$ & $3.5(3.2)$ \\
\hline $\begin{array}{l}\text { No. (\%) of subjects } \\
\text { with high GH }\end{array}$ & $22(49)$ & $10(23)$ & $11(26)$ \\
\hline \multicolumn{4}{|l|}{ Second colonoscopy } \\
\hline Mean (S.D.) GH & $2.2(2.2)$ & $2.1(2.3)$ & $2.1(1.3)$ \\
\hline $\begin{array}{l}\text { No. (\%) of subjects } \\
\text { with high GH }\end{array}$ & $22(73)$ & $4(13)$ & $4(13)$ \\
\hline \multicolumn{4}{|l|}{ Third colonoscopy } \\
\hline Mean (S.D.) GH & $2.1(2.5)$ & $1.9(1.6)$ & $1.1(0.8)$ \\
\hline $\begin{array}{l}\text { No. }(\%) \text { of subjects } \\
\text { with high GH }\end{array}$ & $7(64)$ & 0 & $4(36)$ \\
\hline \multicolumn{4}{|l|}{ Fourth colonoscopy } \\
\hline Mean (S.D.) GH & $1.9(1.4)$ & $2.2(0.6)$ & $2.1(0)$ \\
\hline $\begin{array}{l}\text { No. (\%) of subjects } \\
\text { with high } \mathrm{GH}\end{array}$ & $3(75)$ & 0 & $1(25)$ \\
\hline
\end{tabular}

GH levels. Mean GH levels were significantly elevated in patients with hyperplastic polyps at the first colonoscopy, but there was no difference in GH levels in patients with different histological findings at each subsequent screening.

Table 4 shows the mean serum IGF1 levels and the IGF1 ratios (compared with the upper limit of the agecorrected normal range) in patients with normal findings, hyperplastic polyps or adenomas at each of the four surveillance colonoscopies. Amongst all 254 patients, IGF1 levels in patients with adenomas at the first colonoscopy were not significantly different compared to patients with normal colons, but those with a hyperplastic polyp had significantly higher IGF1 levels compared with patients with normal colons. Serum IGF1 levels were also elevated in patients with hyperplastic polyps and adenomas at the third surveillance, compared with those with normal colons.

At the second colonoscopy, the prevalence of new adenomas was significantly higher in patients with high IGF1 levels compared with patients with normal IGF1 (24 vs $10 \%$, OR $2.8,95 \%$ confidence interval (CI) $1.28-6.32, P=0.01)$.

There was no significant association between histology at the second colonoscopy and IGF1 levels at the initial screening.

Table 4 Mean (s.D.) serum insulin-like growth factor 1 (IGF1) levels $(\mathrm{ng} / \mathrm{ml}$ ), mean (s.D.) IGF1 ratio (ratio of upper limit of age-related normal range) and number (\%) of patients with normal or high IGF1 levels in those with normal colons, hyperplastic polyps and adenomas at sequential colonoscopic screenings. (IGF1 levels were not available for all patients).

\begin{tabular}{lccc}
\hline & & $\begin{array}{c}\text { Hyper- } \\
\text { plastic } \\
\text { polyps }\end{array}$ & $\begin{array}{c}\text { Tubular } \\
\text { adenomas }\end{array}$ \\
\hline First colonoscopy & Normal & & \\
Mean (s.D.) IGF1 & $299.8(214)$ & $432.5(303)^{\dagger}$ & $340.8(206)$ \\
IGF1 ratio (s.D.) & $1.12(0.7)$ & $1.68(1.14)^{\ddagger}$ & $1.41(0.8)$ \\
Normal IGF1 $(n=103)$ & $71(69 \%)$ & $12(12 \%)$ & $20(19 \%)$ \\
High IGF1 $(n=108)$ & $61(57 \%)$ & $21(19 \%)$ & $26(24 \%)$ \\
Second colonoscopy & & & \\
Mean (s.D.) IGF1 & $244(148)$ & $225(113)$ & $279(130)$ \\
IGF1 ratio (s.D.) & $0.91(0.6)$ & $0.87(0.4)$ & $1.15(0.5)$ \\
Normal IGF1 $(n=93)$ & $61(65 \%)$ & $23(25 \%)$ & $9(10 \%)$ \\
High IGF1 $(n=59)$ & $37(63 \%)$ & $8(13 \%)$ & $14(24 \%)^{*}$ \\
Third colonoscopy & & & \\
Mean (s.D.) IGF1 & $212(112)$ & $303(121)^{\star}$ & $266(147)$ \\
IGF1 ratio (s.D.) & $0.88(0.4)$ & $1.24(0.45)^{\dagger}$ & $1.2(0.63)^{\star}$ \\
Normal IGF1 $(n=29)$ & $20(69 \%)$ & $5(17 \%)$ & $4(14 \%)$ \\
High IGF1 $(n=26)$ & $13(50 \%)$ & $9(35 \%)$ & $4(15 \%)$ \\
Fourth colonoscopy & & & \\
Mean (s.D.) IGF1 & $233(81)$ & $173(45)$ & $272(45)$ \\
IGF1 ratio (s.D.) & $1.07(0.4)$ & $0.84(0.27)$ & $1.12(0.13)$ \\
Normal IGF1 $(n=5)$ & $3(60 \%)$ & $2(40 \%)$ & $0(0 \%)$ \\
High IGF1 $(n=6)$ & $3(50 \%)$ & $1(17 \%)$ & $2(33 \%)$ \\
\hline
\end{tabular}

${ }^{\star} P<0.05 ;{ }^{\dagger} P<0.01 ;{ }^{\ddagger} P<0.005$. 
Table 5 Number of patients (\%) with normal colon (N), hyperplastic polyp (H) or tubular adenoma $(\mathrm{A})$ at follow-up colonoscopic screenings according to the findings at the original colonoscopy.

\begin{tabular}{|c|c|c|c|c|c|c|c|c|c|}
\hline \multirow{2}{*}{$\begin{array}{l}\text { Findings at original } \\
\text { colonoscopic } \\
\text { screening }\end{array}$} & \multicolumn{3}{|c|}{ Second colonoscopy } & \multicolumn{3}{|c|}{ Third colonoscopy } & \multicolumn{3}{|c|}{ Fourth colonoscopy } \\
\hline & $\mathrm{N}(n=97)$ & $\mathrm{H}(n=31)$ & $\mathrm{A}(n=24)$ & $\mathrm{N}(n=37)$ & $\mathrm{H}(n=14)$ & $\mathrm{A}(n=8)$ & $\mathrm{N}$ & $\mathrm{H}$ & $A$ \\
\hline Normal colon & $68(78 \%)$ & $12(14 \%)$ & $7(8 \%)$ & 19 (79\%) & $4(17 \%)$ & $1(4 \%)$ & $0(0 \%)$ & $2(100 \%)$ & $0(0 \%)$ \\
\hline Hyperplastic polyp & $8(32 \%)$ & $12(48 \%)$ & $5(20 \%)$ & $7(54 \%)$ & $5(38 \%)$ & $1(8 \%)$ & $1(50 \%)$ & $1(50 \%)$ & $0(0 \%)$ \\
\hline Adenoma & $21(54 \%)$ & $7(18 \%)$ & $12(28 \%)$ & $11(50 \%)$ & $5(23 \%)$ & $6(27 \%)$ & $6(67 \%)$ & $0(0 \%)$ & $3(33 \%)$ \\
\hline
\end{tabular}

\section{Association between polyps at initial colonoscopy and subsequent screenings}

The histological findings at the initial colonoscopic surveillance influenced the findings at subsequent colonoscopies (Table 5). The presence of an adenoma rather than normal colon at the first colonoscopy was associated with an increased risk of adenoma at all subsequent colonoscopic procedures: second colonoscopy (28 vs $8 \%$ respectively, OR $4.4 ; 95 \%$ CI $1.9-10.4$; $P<0.001$ ), third colonoscopy (27 vs $4 \%$ respectively, OR 8.8, 95\% CI 2.9-26.5, $P<0.001$ ) and fourth colonoscopy ( 33 vs $0 \%$ respectively, $P=N S$ ). Similarly, a hyperplastic polyp rather than a normal colon at the first colonoscopy was associated with a hyperplastic polyp at the second and third surveillance (48 vs $12 \%$, OR 6.7, 95\% CI 3.3-13.9; $P<0.001$ and 38 vs $17 \%$, OR 2.9 , 95\% CI 1.5-5.8; $P<0.01$ respectively). The presence of any polyp (hyperplastic or adenoma) at the first colonoscopy rather than a normal colon was associated with a 4.6 -fold increased risk ( 55 vs $21 \%$; OR $4.6,95 \%$ CI 2.5-8.6; $P<0.001$ ) of a polyp at the second screen. Conversely, a normal colon at the first surveillance gave a high probability of normal findings at the second $(78 \%)$ or third surveillance $(79 \%)$.

Of all patients who had an adenoma at the second, third and fourth colonoscopies, 50\% (12/24), 75\% $(6 / 8)$ and $100 \%(3 / 3)$ respectively had an adenoma at the initial colonoscopy.

The association between the presence of polyps at colonoscopy and findings at subsequent surveillances also held for the second colonoscopy, in that an adenoma or hyperplastic polyp rather than a normal colon was associated with an increased risk of an adenoma or hyperplastic polyp at the third screening (25 vs 3\%, OR 11, 95\% CI 3.1-37.1; $P<0.001$ and 46 vs $16 \%$, OR 4.5, 95\% CI 2.3-8.7; $P<0.01$ respectively). Conversely, a normal second colonoscopy was associated with a normal third screening in $81 \%$ of patients.

\section{Association between polyps + IGF1 levels together at initial colonoscopy and subsequent surveillance findings}

The patients were classified into four groups according to the combination of histology at the initial colonoscopy and IGF1 levels, i.e. negative colonoscopy and normal IGF1 (group 1); negative colonoscopy and high IGF1 (group 2); positive colonoscopy (any polyp) and normal IGF1 (group 3); and positive colonoscopy and high IGF1 (group 4). Table 6 details the number and proportion of patients with normal colon, hyperplastic polyps and new adenomas at the second surveillance in these four groups: $81 \%$ of patients in group 1 had a negative second colonoscopy compared to $49 \%$ of those in group 4 . Conversely, the proportion of patients with an adenoma at the second colonoscopy was $24 \%$ in group 4 compared with $2 \%$ in group 1 (OR 15.5, 95\% CI 3.5-67.5; P<0.001).

\section{Discussion}

Most authorities now accept that patients with acromegaly have an increased risk of colorectal neoplasia, even if the exact degree of risk remains uncertain $(18,21-27)$. In the non-acromegalic

Table 6 Number (\%) of patients with normal colon, hyperplastic or adenomatous polyp at the second colonoscopy according to the combined histology insulin-like growth factor 1 (IGF1) levels at the original colonoscopy.

\begin{tabular}{|c|c|c|c|}
\hline \multirow[b]{2}{*}{ Findings at initial colonoscopy } & \multicolumn{3}{|c|}{ Findings at second colonoscopy } \\
\hline & Normal colon & Hyperplastic polyp & Adenomatous polyp \\
\hline Normal colon and controlled disease (group $1 ; n=42$ ) & $34(81 \%)$ & $7(17 \%)$ & $1(2 \%)$ \\
\hline Normal colon and high IGF1 (group $2 ; n=33$ ) & $24(73 \%)$ & $4(12 \%)$ & $5(15 \%)$ \\
\hline Polyp and controlled disease (group $3 ; n=24$ ) & $12(50 \%)$ & $5(10 \%)$ & $7^{*}(29 \%)$ \\
\hline Polyp and high IGF1 (group $4 ; n=37$ ) & $18(49 \%)$ & $10(27 \%)$ & $9^{*}(24 \%)$ \\
\hline
\end{tabular}

${ }^{\star} P<0.005$ for prevalence of adenomas compared to group 1 . 
population, the majority of colonic cancers develop from pre-malignant colonic adenomas, and several studies have demonstrated that colonoscopic screening and removal of adenomas reduce the incidence of colorectal cancer. There is also some evidence that hyperplastic polyps may be pre-malignant or be associated with an increased risk of future malignancy $(15,16,28,29)$. With this in mind, colonoscopic screening has been increasingly offered to patients with acromegaly. However, the frequency with which this should be performed remains unclear. A recent consensus document recommended that the frequency of follow-up surveillance should be the same as the general population (18). Based on our findings from a previous study, we suggested that the frequency should be 3-5 yearly: 3 yearly for patients who had an adenoma or who had elevated serum IGF1 levels and 5 yearly in other patients (19). The present study details our cumulative experience of a large cohort in a single centre over a 15-year period. Our results extend our earlier findings and allow for revision and optimisation of the guidelines.

The frequency of new polyps at the second and third colonoscopies was very similar. After a mean interval of $\sim 4$ years between each colonoscopy, the overall incidence of new polyps at the second and third surveillance was 36 and $37 \%$ respectively, compared with $38 \%$ at the initial screening. The higher incidence of $47 \%$ at the fourth colonoscopy may reflect a higher risk group, as well as the smaller number of patients. The fact that at each colonoscopy more than one-third of patients had a polyp supports the need for a regular surveillance programme.

The success of our surveillance programme may be judged from the fact that no cancers were discovered during the third or fourth colonoscopies. The single cancer at the second colonoscopy was discovered in a patient who underwent the initial screening colonoscopy at a different institution; at that time, the hepatic flexure was reported to be normal, but the second examination 18 months later revealed a carcinoma in the transverse colon and four adenomas. Although these lesions have been classified here as being new, it is more probable that they were missed at the original screening. This emphasises the need for visualisation to the caecum by an experienced operator. The advantage of the present study is that it reflects the experience of a single large cohort of patients from a single institution, and all the colonoscopies, except two, were performed by the same skilled operator, who visualised the entire colon in $99 \%$ of procedures. For less experienced operators, the success rate is only $70 \%$ (11).

This study has further clarified the influence of $\mathrm{GH}$ and IGF1 in the development of colonic polyps. At the first colonoscopy, patients with hyperplastic polyps had significantly higher GH and IGF1 levels than those with normal colons. This was also the case at the third colonoscopy when patients with both hyperplastic polyps and adenomas had higher IGF1 ratios. The absence of any significant association at the second colonoscopy is initially puzzling as our previous analysis of 66 patients undergoing a second colonoscopy revealed the eight patients with a new adenoma to have significantly higher IGF1 levels (19). However, the current size of the cohort undergoing a second colonoscopy is almost threefold larger, and although IGF1 levels were higher in those with a new adenoma, statistical significance was not achieved. One reason for the apparent discrepancy might be the introduction of new medical treatments, such as somatostatin analogues and more recently GH antagonists, which has enabled more effective control of disease activity reflected in the progressive lowering of mean IGF1 levels amongst the entire cohort at each successive colonoscopy. Certainly, at the second surveillance, the majority of patients had IGF1 levels within the normal range. Thus, the number of patients with poorly controlled acromegaly is very low. However, supporting a role for IGF1 in the development of new adenomas is that at the second screening, patients with elevated IGF1 levels had a 2.8-fold increased prevalence of neoplasia compared to patients with controlled disease, although $10 \%$ of the latter still had an adenoma. An even more striking effect was noted in those patients with a normal initial colonoscopy in whom an elevated IGF1 level was associated with a 7.5-fold increased risk of a subsequent adenoma.

Our findings on the influence of IGF1 are largely in agreement with previous studies by other groups in smaller series over shorter follow-up periods (12). Bogazzi et al. recently reported on yearly colonoscopic screening over a 5-year period and observed IGF1 levels to be higher in individuals who developed multiple new adenomas (30). This influence of IGF1 in the development of colonic neoplasia is in keeping with its known proliferative and anti-apoptotic effects, and increased proliferation of the colonic epithelium in proportion to IGF1 levels has been recorded in acromegalic individuals (31). Furthermore, in the non-acromegalic population, individuals with higher IGF1 levels have an increased risk of developing colonic cancer $(32,33)$. In addition to the endocrine actions of IGF1, a paracrine or autocrine role within the colonic epithelium cannot be excluded, perhaps in response to circulating GH. Certainly, the latter has been reported to exert direct anti-apoptotic effects in human colon cancer cells (34). It is possible that other factors might also be responsible for adenoma recurrence, such as hyperinsulinaemia, diabetes mellitus or altered bowel transit times. A further possibility might relate to the use of somatostatin analogue therapy. While this was not directly investigated in this study, we found no association between somatostatin analogue use and prevalence of colorectal neoplasia in our original study (11).

This study had several limitations. First, was the absence of a control group for the study, although this 
is the case in the majority of retrospective studies of the prevalence of colorectal neoplasia in acromegaly. In addition, not all patients attended the second and third colonoscopies. Reasons for this included the patient's unwillingness to undertake the procedure, being lost to follow-up, moving away from the hospital catchment area, or other morbidity. However, this does not detract from the main findings of the present study, namely those factors which are associated with polyp recurrence.

Our findings demonstrated a high incidence of hyperplastic polyps, with $\sim 20 \%$ of patients at each colonoscopy having a new hyperplastic polyp. These also appear to be related to high IGF1 levels, perhaps as a result of its pro-proliferative actions. In the non-acromegalic population, the influence of hyperplastic polyps in the malignant process is controversial; while they have traditionally been regarded as benign, several recent studies suggest that they may also have a potential to become malignant or act as markers for the subsequent development of colorectal cancer $(15,16$, $28,29)$. Therefore, with regard to developing screening guidelines for patients with acromegaly, it may be prudent to take into account the influence of all polyps rather than adenomas alone.

Certainly, in addition to IGF1, the presence of a polyp (adenoma or hyperplastic) at the initial screening is the other major determining factor for the development of new polyps. Patients with an initial adenoma had a 4.4to 8.8-fold increased risk of developing an adenoma at the second and third colonoscopies, and this association was even stronger for the presence of any polyp at the initial surveillance. Conversely, a negative initial screen was highly predictive of subsequent negative colonoscopies, even up to 15 years after the initial screen. This association between the presence of neoplasia influencing future risk also held for the second screen, and is in keeping with other recent studies and also in the non-acromegalic population in whom there was a 2- and 3.5-fold increased risk of adenoma or hyperplastic polyp recurrence in patients with adenomas or hyperplastic polyps respectively at the initial colonoscopy $(24,35)$. The association in the current study was even stronger when IGF1 levels were also taken into account, and in particular, the combination of a normal initial colonoscopy and normal IGF1 levels was associated with an $81 \%$ chance of a negative follow-up colonoscopy.

Taken together, it seems that identification of those at risk of future colonic neoplasia can largely be determined by the findings at the initial colonoscopic evaluation together with the activity of the underlying acromegaly. Whether this persistent predisposition for neoplasia is a reflection of a generalised hyperproliferative epithelium or a genetic predisposition for malignant transformation of adenomas remains uncertain. The majority of the adenomas recorded in the follow-up colonoscopies were small, with a maximum size of
$10 \mathrm{~mm}$. In the non-acromegalic population, the risk of malignant transformation is generally considered significant for polyps $>10 \mathrm{~mm}$ diameter and is thought to take 10-20 years. Whether this is also true for the acromegalic bowel is uncertain. The precise local environmental conditions which predispose to the increased risk of malignancy in acromegaly remain uncertain, but it may be appropriate to assume an accelerated process given that the analysis of all colonoscopic screening studies in acromegalic patients indicates a 2.4-fold increased risk of adenomas but a sixfold risk of an actual cancer (22). It is possible that some of this discrepancy might be accounted for by a malignant transformation of the hyperplastic polyps. While recent guidelines for colorectal cancer screening in the non-acromegalic population suggest that 10-yearly colonoscopic screening beginning at the age of 50 years is adequate, this may not be safe for patients with acromegaly, and more regular colonoscopic screening may be required for some patients (33). Although the numbers of patients with new adenomas or hyperplastic polyps in the current study are too few for formal statistical risk calculation, based on our current long-term data, it would seem appropriate to modify our recommendations to 5-yearly surveillance in patients with either a polyp at the initial screen or an elevated serum IGF1 level, and to reduce surveillance to every 10 years for the remaining low-risk patients. Amongst the latter patients, the presence of a polyp at a subsequent surveillance should warrant their reclassification to a higher risk with subsequent 5-yearly surveillance. The age as to when screening should begin is uncertain. While a recent consensus document has suggested that a screening colonoscopy should be performed on all acromegalic patients at diagnosis irrespective of their age, we suggest that surveillance should begin at the age of 40 years, as in our original study, the earliest age of patients with an adenoma was 39 years and the cancers occurred in older patients (11). This would avoid performing the invasive procedure on younger patients in whom the chances of an adenoma/ cancer being present are very low. Given the high prevalence of polyps at follow-up screening in patients with acromegaly, it may be appropriate to perform fibre optic colonoscopy rather than computerised tomography (CT) colonography.

\section{Conclusions}

Repeated colonoscopic screening of patients with acromegaly over a 15-year period has demonstrated a high prevalence of new adenomatous and hyperplastic colonic polyps. It suggests that patients with acromegaly at high risk of developing new colonic neoplasia are those with a polyp at the initial screen and/or who have uncontrolled disease with high IGF1 levels. As such, it would seem appropriate to modify our 
recommendations to 5-yearly surveillance in these patients, while for the remaining low-risk patients it is probably safe to reduce surveillance to every 10 years.

\section{Declaration of interest}

The authors declare that there is no conflict of interest that could be perceived as prejudicing the impartiality of the research reported.

\section{Funding}

This research did not receive any specific grant from any funding agency in the public, commercial or not-for-profit sector.

\section{Acknowledgements}

D Dworakowska would like to thank the Polish Science Foundation for a post-doctoral fellowship to Barts and the London School of Medicine, London, UK.

\section{References}

1 Klein I, Parveen G, Gavaler JS \& Vanthiel DH. Colonic polyps in patients with acromegaly. Annals of Internal Medicine 198297 27-30.

2 Ituarte EM, Petrini J \& Hershman JM. Acromegaly and colon cancer. Annals of Internal Medicine 1984101 627-628.

3 Brunner JE, Johnson CC, Zafar S, Peterson EL, Brunner JF \& Mellinger RC. Colon cancer and polyps in acromegaly: increased risk associated with family history of colon cancer. Clinical Endocrinology 199032 65-71.

4 Ezzat S, Strom C \& Melmed S. Colon polyps in acromegaly. Annals of Internal Medicine $1991 \mathbf{1 1 4}$ 754-755.

5 Vasen HF, van Erpecum KJ, Roelfsema F, Raue F, Koppeschaar H, Griffioen G \& van Berge Henegouwen GP. Increased prevalence of colonic adenomas in patients with acromegaly. European Journal of Endocrinology 1994131 235-237.

6 Terzolo M, Tappero G, Borretta G, Asnaghi G, Pia A, Reimondo G, Boccuzzi A, Cesario F, Rovero E, Paccotti P \& Angeli A. High prevalence of colonic polyps in patients with acromegaly. Influence of sex and age. Archives of Internal Medicine $1994 \mathbf{1 5 4}$ 1272-1276.

7 Ortego J, Vega B, Sampedro J, Escalada J, Boixeda D \& Varela C. Neoplastic colonic polyps in acromegaly. Hormone and Metabolic Research 199426 609-610.

8 Ladas SD, Thalassinos NC, Ioannides G \& Raptis SA. Does acromegaly really predispose to an increased prevalence of gastrointestinal tumours? Clinical Endocrinology $1994 \mathbf{4 1}$ $597-601$.

9 Delhougne B, Deneux C, Abs R, Chanson P, Fierens H, LaurentPuig P, Duysburgh I, Stevenaert A, Tabarin A \& Delwaide J. The prevalence of colonic polyps in acromegaly: a colonoscopic and pathological study in 103 patients. Journal of Clinical Endocrinology and Metabolism 199580 3223-3226.

10 Colao A, Balzano A, Ferone D, Panza N, Grande G, Marzullo P, Bove A, Iodice G, Merola B \& Lombardi G. Increased prevalence of colonic polyps and altered lymphocyte subset pattern in the colonic lamina propria in acromegaly. Clinical Endocrinology 1997 $4723-28$.

11 Jenkins PJ, Fairclough PD, Richards T, Lowe DG, Monson J, Grossman A, Wass JAH \& Besser GM. Acromegaly, colonic polyps and carcinoma. Clinical Endocrinology 199747 17-22.
12 Terzolo M, Reimondo G, Gasperi M, Cozzi R, Pivonello R, Vitale G, Scillitani A, Attanasio R, Cecconi E, Daffara F, Gaia E, Martino E, Lombardi G, Angeli A \& Colao A. Colonoscopic screening and follow-up in patients with acromegaly: a multicenter study in Italy. Journal of Clinical Endocrinology and Metabolism 200590 84-90.

13 Muto T, Bussey HJ \& Morson BC. The evolution of cancer of the colon and rectum. Cancer 197536 2251-2270.

14 Selby JV, Friedman GD, Quesenberry CP \& Weiss NS. A casecontrol study of screening sigmoidoscopy and mortality from colorectal cancer. New England Journal of Medicine 1992326 653-657.

15 Jass JR. Hyperplastic polyps and colorectal cancer: is there a link? Clinical Gastroenterology and Hepatology 2004 2 1-8.

16 Wynter CV, Walsh MD, Higuchi T, Leggett BA, Young J \& Jass JR. Methylation patterns define two types of hyperplastic polyp associated with colorectal cancer. Gut 200453 573-580.

17 Atkin WS, Morson BC \& Cuzick J. Long-term risk of colorectal cancer after excision of rectosigmoid adenomas. New England Journal of Medicine 1992326 658-662.

18 Melmed S, Colao A, Barkan A, Molitch M, Grossman AB, Kleinberg D, Clemmons D, Chanson P, Laws E, Schlechte J, Vance ML, Ho K \& Giustina A. Guidelines for acromegaly management: an update. Journal of Clinical Endocrinology and Metabolism 200994 1509-1517.

19 Jenkins PJ, Frajese V, Jones AM, Camacho-Hubner C, Lowe DG, Fairclough PD, Chew SL, Grossmann AB, Monson J \& Besser GM. IGF-I and the development of colorectal neoplasia in acromegaly. Journal of Clinical Endocrinology and Metabolism $2000 \mathbf{8 5}$ 3218-3221.

20 Morrell DJ, Dadi H, More J, Taylor AM, Dabestani A, Buchanan CR, Holder AT \& Preece MA. A monoclonal antibody to human insulin-like growth factor-I: characterization, use in radioimmunoassay and effect on the biological activities of the growth factor. Journal of Molecular Endocrinology 19892 201-206.

21 Ezzat S \& Melmed S. Clinical review 18: are patients with acromegaly at increased risk for neoplasia? Journal of Clinical Endocrinology and Metabolism 199172 245-249.

22 Jenkins PJ \& Besser M. Clinical perspective: acromegaly and cancer: a problem. Journal of Clinical Endocrinology and Metabolism $2001862935-2941$.

23 Turner HE \& Wass JA. Modern approaches to treating acromegaly. Quarterly Journal of Medicine 200093 1-6.

24 Renehan AG, Bhaskar P, Painter JE, O'Dwyer ST, Haboubi N, Varma J, Ball SG \& Shalet SM. The prevalence and characteristics of colorectal neoplasia in acromegaly. Journal of Clinical Endocrinology and Metabolism 200085 3417-3424.

25 Renehan AG, O'Dwyer ST \& Shalet SM. Guidelines for colonoscopic screening in acromegaly are inconsistent with those for other high risk groups. Gut 200352 1071-1072.

26 Loeper S \& Ezzat S. Acromegaly: re-thinking the cancer risk. Reviews in Endocrine and Metabolic Disorders 2008 9 41-58.

27 Rokkas T, Pistiolas D, Sechopoulos P, Margantinis G \& Koukoulis G. Risk of colorectal neoplasm in patients with acromegaly: a metaanalysis. World Journal of Gastroenterology 200814 3484-3489.

28 Fraser GM \& Niv Y. Hyperplastic polyp and colonic neoplasia: is there an association? Journal of Clinical Gastroenterology 199316 278-280.

29 Cats A, Dullaart RP, Kleibeuker JH, Kuipers F, Sluiter WJ, Hardonk MJ \& de Vries EG. Increased epithelial cell proliferation in the colon of patients with acromegaly. Cancer Research $1996 \mathbf{5 6}$ 523-526.

30 Bogazzi F, Cosci C, Sardella C, Costa A, Manetti L, Gasperi M, Rossi G, Bartalena L \& Martino E. Identification of acromegalic patients at risk of developing colonic adenomas. Journal of Clinical Endocrinology and Metabolism 200691 1351-1356.

31 Manousos O, Souglakos J, Bosetti C, Tzonou A, Chatzidakis V, Trichopoulos D, Adami HO \& Mantzoros C. IGF-I and IGF-II in relation to colorectal cancer. International Journal of Cancer 1999 $8315-17$. 
32 Ma J, Pollak M, Giovannucci E, Chan JM, Tao Y, Hennekens CH \& Stampfer MJ. Prospective study of colorectal cancer risk in men and plasma levels of insulin like growth factor (IGF)-1 and IGF-binding protein-3. Journal of the National Cancer Institute 199991 620-625.

33 Bogazzi F, Ultimieri F, Raggi F, Russo D, Vanacore R, Guida C, Brogioni S, Cosci C, Gasperi M, Bartalena L \& Martino E. Growth hormone inhibits apoptosis in human colonic cancer cell lines: antagonistic effects of peroxisome proliferator activated receptorgamma ligands. Endocrinology 2004145 3353-3362.

34 Bensen SP, Cole BF, Mott LA, Baron JA, Sandler RS \& Haile R. Colorectal hyperplastic polyps and risk of recurrence of adenomas and hyperplastic polyps. Polyps Prevention Study. Lancet 1999 354 1873-1874.
35 Levin B, Lieberman DA, McFarland B, Smith RA, Brooks D, Andrews KS, Dash C, Giardiello FM, Glick S, Levin TR, Pickhardt P, Rex DK, Thorson A \& Winawer SJ. Screening and surveillance for the early detection of colorectal cancer and adenomatous polyps, 2008: a joint guideline from the American Cancer Society, the US Multi-Society Task Force on Colorectal Cancer, and the American College of Radiology. CA: A Cancer Journal for Clinicians $20085 \mathbf{5 8}$ 130-160.

Received 16 April 2010

Accepted 29 April 2010 